\title{
Simvastatin reduced mortality and vascular events
}

\author{
MRC/BHF Heart Protection Study of cholesterol lowering with simvastatin in 20536 high-risk individuals: \\ a randomised placebo-controlled trial. Lancet 2002;360:7-22.
}

\section{QUESTION: In patients with a high 5 year risk of death, does simvastatin reduce mortality and vascular events?}

Design

Randomised (allocation concealed*), blinded (participants, clinicians, data collectors, and outcome assessors),* placebo controlled trial with mean follow up of 5 years.

Sources of funding: UK Medical Research Council; British Heart Foundation; Merck E Co; Roche Vitamins.

For correspondence: Heart Protection Study, Clinical Trial Service Unit, Radcliffe Infirmary, Oxford, UK hps@ctsu.ox.ac.uk

Abstract and commentary also published in $A C P$ Journal Club

\section{Setting \\ 69 UK hospitals.}

\section{Patients}

20536 patients who were $40-80$ years of age (28\% were $\geq 70$ y of age, $75 \%$ men); had nonfasting total cholesterol levels $\geq 3.5 \mathrm{mmol} / \mathrm{l}$; and had a substantial 5 year risk of death because of a history of coronary heart disease (CHD), occlusive disease of noncoronary arteries, or diabetes mellitus or a history of treated hypertension (in men $\geq 65$ y of age). Exclusion criteria included a clear indication for statin therapy according to the patient's doctor; abnormal liver or renal function; muscle

Table 1. Simvastatin v placebo in high risk patients at mean 5 year follow upt

\begin{tabular}{lcccl} 
Outcomes & \multicolumn{2}{c}{ Simvastatin Placebo } & RRR (95\% CI & NNT (CI) \\
All cause mortality & $13 \%$ & $15 \%$ & $13 \%(6$ to 19$)$ & 58 (37 to 128$)$ \\
\hline Vascular mortality & $7.6 \%$ & $9.1 \%$ & $17 \%(9$ to 25$)$ & 66 (44 to 134$)$ \\
\hline Nonvascular mortality & $5.3 \%$ & $5.6 \%$ & $5 \%(-7$ to 15$)$ & Not significant \\
\hline Major coronary event & $8.7 \%$ & $12 \%$ & $27 \%(21$ to 33$)$ & $33(26$ to 46$)$ \\
\hline Stroke & $4.3 \%$ & $5.7 \%$ & $25 \%(15$ to 34$)$ & $73(51$ to 131$)$ \\
\hline Revascularisation & $9.1 \%$ & $12 \%$ & $24 \%(17$ to 30$)$ & $39(29$ to 58$)$ \\
\hline
\end{tabular}

Abbreviations defined in glossary; RRR, NNT, and $\mathrm{Cl}$ calculated from data in article.

$\ddagger$ Nonfatal myocardial infarction or death from coronary disease.

problems; concurrent treatment with cyclosporin, fibrates, or high dose niacin; potential for pregnancy; and serious medical conditions. Follow up was $99.7 \%$.

\section{Intervention}

Run in treatment consisted of 4 weeks of placebo and 4-6 weeks of simvastatin, $40 \mathrm{mg}$ /day. Compliant patients who did not have serious problems during the run in phase were allocated to simvastatin, $40 \mathrm{mg} /$ day $(\mathrm{n}=10269)$, or placebo $(\mathrm{n}=10$ 267). Patients were also randomised in a 2 $\times 2$ factorial design to antioxidant vitamins (vitamin $\mathrm{E}$, $600 \mathrm{mg} / \mathrm{d}$; vitamin $\mathrm{C}, 250 \mathrm{mg} / \mathrm{d}$; and $\beta$-carotene, 20 $\mathrm{mg} / \mathrm{d}$ ) or placebo (see companion report).

\section{Main outcome measures}

All cause, vascular, and nonvascular mortality. Secondary outcomes included major coronary events (nonfatal myocardial infarction or death from CHD); stroke; revascularisation; and cancer.

\section{Main results}

Analysis was by intention to treat. Simvastatin led to a reduction in all cause and vascular mortality, major coronary events, stroke, and revascularization (table 1). Simvastatin and placebo did not differ for nonvascular mortality (table) or cancer incidence.

\section{Conclusion}

In patients with a high 5 year risk of death, simvastatin safely reduced all cause mortality, vascular mortality, and vascular events.

*See glossary.

\section{COMMENTARY}

The MRC/BHF Heart Protection Study (HPS) of cholesterol lowering and antioxidant supplementation in a wide range of high risk persons is the largest randomised trial of CHD prevention to date and should profoundly influence how statins and antioxidants are prescribed. In terms of vascular event prevention, the trial's main message was that risk reductions conferred by long term statin therapy depended chiefly on a person's overall risk of major vascular events rather than on their initial blood lipid level. Also, such benefit was achieved safely. Remarkably, the number needed to treat (NNT) with the statin for 5 years to prevent the first major vascular event was similar across pretreatment cholesterol levels (NNT range 18 [95\% CI 13 to 27 ] to 19 [CI 14 to 30$]$ ]) and age categories (NNT range 16 [CI 11 to 26] to 19 [CI 14 to 36]) and in patients with previous CHD only (NNT 18 [CI 13 to 26]) or diabetes only (NNT 21 [14 to 40]). These observations were also consistent with results from previous statin trials (table 2 on opposite page) in which the greatest benefit (smaller NNT per year) occurred among those at greatest risk. ${ }^{1}$ With increasing age, however, smaller NNTs per year for CHD events may not necessarily yield greater cumulative benefit. ${ }^{2}$ Preventing a CHD event at 50 rather than 70 years of age may yield much greater potential for cumulative benefit (life years and quality of life gained). Thus, contrary to implications of the HPS and the National Cholesterol Education Program (ATP III) guidelines, ${ }^{3}$ greater CHD risk reduction may not parallel greater overall benefit in the elderly.

Antioxidant intervention had no effect on CHD outcomes (or the incidence of cancer) but was associated with minor increases in low density lipoprotein cholesterol and triglyceride levels. These negative findings were in accord with several randomised controlled trials, including the large Heart Outcomes Prevention Evaluation Study. ${ }^{4}$ Thus, the unreal expectations aroused by observational studies and the Cambridge Heart Antioxidant Study (CHAOS) ${ }^{5}$ have been put to rest. Observational studies can mislead owing to unidentified confounding factors, and CHAOS was small, was done in the prestatin era, and had incomplete follow up.

In conclusion, given that benefits conferred by statins are mainly determined by premorbid CHD risk rather than the lipid level, identifying persons with "abnormal" lipid profiles and dosage titration to preset target lipid levels become questionable. It may nevertheless be appropriate to monitor lipid levels during treatment to verify that cholesterol has been lowered to the degree expected. Antioxidants cannot be recommended for CHD prevention. Instead, greater efforts should be directed at implementing appropriate, proven preventive measures (use of aspirin, $\beta$ blockers, angiotensin converting enzyme inhibitors, and statins) in high risk persons.

1 Kumana CR, Cheung BM, Lauder IJ. JAMA 1999;282:1899-901.

Expert Panel on Detection, Evaluation, and Treatment of High Blood Cholesterol in Adults. JAMA 2001;285:2486-97.

Yusuf S, Dagenais G, Pogue J, Bosch J, Sleight P. N Eng J Med 2000;342:154-60.

Stephens NG, Parsons A, Schofield PM, et al. Lancet 1996;347:781-86. 


\title{
Antioxidant vitamins did not reduce death, vascular events, or cancer in high risk patients
}

\author{
MRC/BHF Heart Protection Study of antioxidant vitamin supplementation in 20536 high-risk individuals: \\ a randomised placebo-controlled trial. Lancet 2002;360:23-33.
}

\author{
QUESTION: In patients with a high 5 year risk of death, does antioxidant \\ supplementation reduce death, vascular events, and cancer?
}

\section{Design}

Randomised (allocation concealed*), blinded (participants, clinicians, data collectors, and outcome assessors), ${ }^{*}$ placebo controlled trial with mean follow up of 5 years.

Setting

69 UK hospitals.

\section{Patients}

20536 patients who were $40-80$ years of age (28\% were $\geq 70 \mathrm{y}$ of age, $75 \% \mathrm{men}$ ); had nonfasting total cholesterol levels $\geq 3.5 \mathrm{mmol} / \mathrm{l}$; and had a substantial 5 year risk of death because of a history of coronary heart disease (CHD), occlusive disease of noncoronary arteries, or diabetes mellitus or a history of treated hypertension (in men $\geq 65$ y of age). Exclusion criteria included a clear indication for statin therapy according to the patient's doctor, abnormal liver or renal function, severe heart failure, severe chronic airway disease, cancer, and indication for high dose vitamin $\mathrm{E}$ supplements. Follow up was $99.7 \%$.

\section{Intervention}

Patients received 2 months of active vitamins during a run in phase. Compliant patients without serious problems during the run in phase were allocated to antioxidant vitamins (synthetic vitamin E, $600 \mathrm{mg} / \mathrm{d}$, plus vitamin C, $250 \mathrm{mg} / \mathrm{d}$, plus $\beta$-carotene, $20 \mathrm{mg} / \mathrm{d}$ ) $(n=10269)$ or placebo $(n=10267)$. Patients were also randomised in a $2 \times 2$ factorial design to simvastatin, 40 $\mathrm{mg} /$ day, or placebo.
Main outcome measures

All cause, vascular, and nonvascular mortality. Secondary outcome measures included major coronary events (nonfatal myocardial infarction or death from CHD); stroke; revascularisation; and cancer.

Main results

Analysis was by intention to treat. Antioxidants did not differ from placebo for any outcome (table 1).

\section{Conclusion}

In patients with a high 5 year risk of death, antioxidant vitamins did not reduce mortality, coronary events, stroke, revascularisation, or cancer.

*See glossary.

Sources of funding: UK Medical Research Council; British Heart Foundation; Merck $\mathcal{E}^{\circ}$ Co;Roche Vitamins.

For correspondence: Heart Protection Study, Clinical Trial Service Unit, Radcliffe Infirmary, Oxford, UK. hps@ctsu.ox.ac.uk

Abstract and commentary also published in ACP Journal Club

Table 1. Antioxidant vitamins v placebo for high risk patients at mean 5 year follow upt

\begin{tabular}{lllll} 
Outcomes & $\begin{array}{l}\text { Antioxidant } \\
\text { vitamins }\end{array}$ & Placebo & RRI (95\% CI) & NNH \\
\hline All cause mortality & $14.1 \%$ & $13.5 \%$ & $4 \%(-3$ to 12$)$ & Not significant \\
\hline Vascular mortality & $8.6 \%$ & $8.2 \%$ & $5 \%(-5$ to 15$)$ & Not significant \\
\hline Nonvascular mortality & $5.5 \%$ & $5.3 \%$ & $4 \%(-8$ to 17$)$ & Not significant \\
\hline Major coronary eventł & $10.4 \%$ & $10.2 \%$ & $2 \%(-6$ to 11$)$ & Not significant \\
\hline $\begin{array}{l}\text { Stroke } \\
\text { Revascularisation }\end{array}$ & $10.3 \%$ & $10.6 \%$ & $2 \%(-6$ to 10$)$ & Not significant \\
\hline $\begin{array}{l}\text { Cancer (except } \\
\text { nonmelanoma skin } \\
\text { cancer) }\end{array}$ & $7.0 \%$ & $5.0 \%$ & $1 \%(-12$ to 13$)$ & Not significant \\
\hline
\end{tabular}

tAntioxidant vitamins were vitamin $\mathrm{E}$, vitamin $\mathrm{C}$, and $\beta$ carotene. Abbreviations defined in glossary; RRI, RRR, $\mathrm{NNT}, \mathrm{NNH}$, and $\mathrm{Cl}$ calculated from data in article.

$\ddagger$ Nonfatal myocardial infarction or death from coronary disease.

Table 2. Coronary heart disease (CHD) event prevention for statins v placebo*

\begin{tabular}{|c|c|c|c|c|c|}
\hline $\begin{array}{l}\text { Individual trials (combined } \\
\text { trials) } \dagger\end{array}$ & Patient group & $\begin{array}{l}\text { Mean or median } \\
\text { follow up }\end{array}$ & RRR (95\% CI) & NNT (Cl) & NNT/year (CI) \\
\hline a) AFCAPS/TexCAPS & No CHD, normal cholesterol & 5.4 years & $37 \%(21$ to 50$)$ & 49 (33 to 99$)$ & 256 (170 to 514$)$ \\
\hline b) WOSCOPS & No CHD, high cholesterol & 4.9 years & $31 \%(17$ to 43$)$ & 44 (29 to 95$)$ & 217 (141 to 463$)$ \\
\hline c) CARE & CHD, normal cholesterol & 5.0 years & $24 \%$ (9 to 36$)$ & 33 (20 to 99 ) & 167 (100 to 496) \\
\hline d) LIPID & $\mathrm{CHD}$, normal cholesterol & 6.1 years & $24 \%(12$ to 35$)$ & 28 (20 to 48$)$ & 172 (122 to 294$)$ \\
\hline e) $4 \mathrm{~S}$ & $\mathrm{CHD}$, high cholesterol & 5.2 years & $34 \%(25$ to 41$)$ & 12 (9 to 17$)$ & 63 (49 to 89$)$ \\
\hline$(a+b)$ & No CHD & 5.2 years & $33 \%(22$ to 42$)$ & 47 (34 to 74 ) & 237 (177 to 382$)$ \\
\hline$(c+d+e)$ & $\mathrm{CHD}$ & 5.4 years & $26 \%$ (20 to 31$)$ & 23 (19 to 31$)$ & 129 (103 to 172$)$ \\
\hline$(a+c+d)$ & Normal cholesterol & 5.5 years & $25 \%(18$ to 31$)$ & 39 (30 to 55$)$ & 209 (163 to 398$)$ \\
\hline$(b+e)$ & High cholesterol & 5.2 years & $30 \%(23$ to 37$)$ & 29 (22 to 43$)$ & 151 (114 to 221 ) \\
\hline
\end{tabular}

*AFCAPS/TexCAPS = AirForce/Texas Coronary Atherosclerosis Prevention Study; WOSCOPS = West of Scotland Coronary Prevention Study; CARE = Cholesterol and Recurrent Events; LIPID = Long-term Intervention with Pravastatin in Ischaemic Disease trial; $4 \mathrm{~S}=$ Scandinavian Simvastatin Survival Study. Abbreviations defined in glossary. Data adapted from Kumana et al, ${ }^{1}$ which contains references for these trials. The combined NNT/year for secondary prevention trials was lower than that for primary prevention and for individual trials only that for $4 \mathrm{~S}$ was lower than the others ( $<<0.05$ ). tResults are weighted for combined trials. 